\title{
Images in Clinical Tropical Medicine \\ Lichenoid Skin Nodules as Presenting Feature of Necrotic Erythema Nodosum Leprosum in Leprosy
}

\author{
Akanksha Kaushik, Sunil Dogra, and Tarun Narang* \\ Department of Dermatology, Venereology and Leprology, Postgraduate Institute of Medical Education and Research, Chandigarh, India
}

An 18-year-old male presented with painful papulo-nodular lesions on the upper limbs and back along with high-grade fever since 1 week. Most lesions had a lichenoid center with surrounding blisters (Figure 1A). There was associated tenderness and thickening of bilateral ulnar nerves. Slit skin smear was positive for Mycobacterium leprae (with a bacteriological index of $6+$ and a morphological index of $0 \%$ ) (Figure 1B). Skin biopsy revealed features of lepromatous leprosy (LL) with erythema nodosum leprosum (ENL) including granulomas, nerve destruction, vasculitis, and panniculitis, and lepra stain was positive (Figure 1C). Over the next 2 weeks, most lesions developed ulceration, suggesting necrotic ENL (Figure 1D). The patient is currently receiving $\mathrm{WHO}$-recommended multidrug therapy (MDT) with oral corticosteroids.

Erythema nodosum leprosum is a type III hypersensitivity reaction presenting as erythematous, tender papulo-nodules, commonly on extremities, with histology showing granulomatous inflammation with neutrophil infiltration, and variable degrees of panniculitis and vasculitis. ${ }^{1,2}$ Reported incidence of ENL in multibacillary leprosy (especially LL) is as high as $11.8 \%$. $^{3}$ The lesions usually appear after starting MDT, although it may sometimes be the presenting feature. ${ }^{4}$ Rarely, ENL may be associated with ulceration, producing necrotic ENL, also called erythema necroticans. Necrotic ENL is a severe form often associated with systemic complications and heals with scarring. ${ }^{5}$ The case illustrates that lichenoid skin nodules may be an unusual initial presentation of necrotic ENL.

Received March 8, 2020. Accepted for publication March 24, 2020.

Acknowledgment: We thank Bishan Das Radotra for his inputs regarding histopathological diagnosis.

Authors' addresses: Akanksha Kaushik, Sunil Dogra, and Tarun Narang, Department of Dermatology, Venereology and Leprology, Postgraduate Institute of Medical Education and Research, Chandigarh, India, E-mails: akskaushikk@gmail.com, sundogra@hotmail.com, and narangtarun@yahoo.co.in.

This is an open-access article distributed under the terms of the Creative Commons Attribution (CC-BY) License, which permits unrestricted use, distribution, and reproduction in any medium, provided the original author and source are credited.

\section{REFERENCES}

1. Lockwood DNJ, Nicholls $P$, Smith WCS, Das $L$, Barkataki $P$, van Brakel W, Suneetha S, 2012. Comparing the clinical and

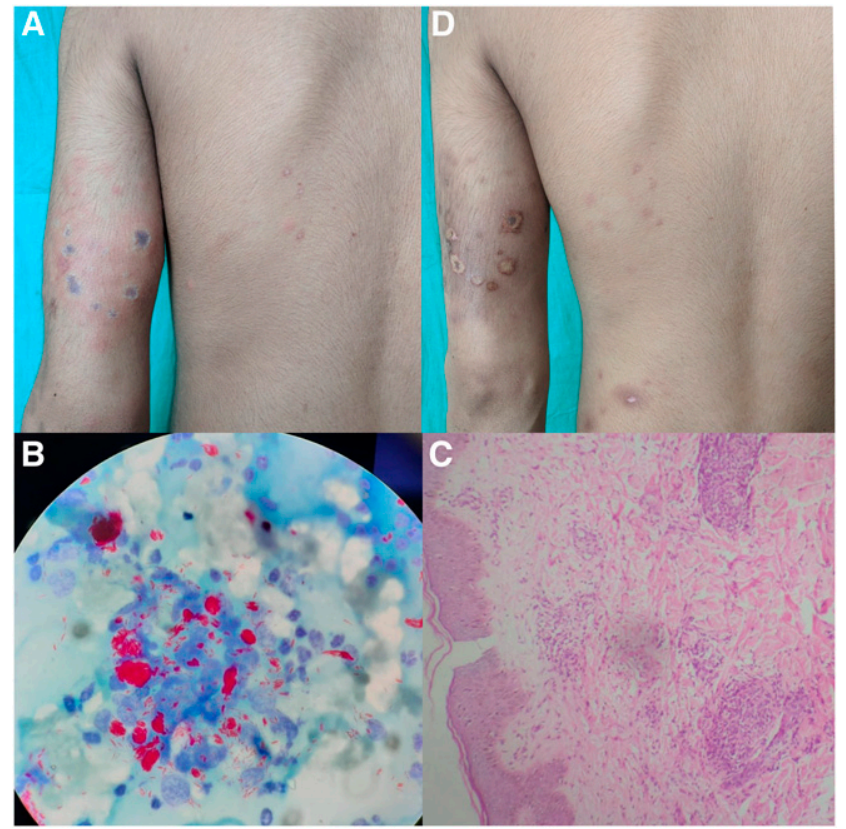

Figure 1. (A) Patient with multiple papulo-nodules, having a lichenoid center with surrounding blisters, on upper limb and back. (B) Slit skin smear of the same patient showing acid fast bacilli. (C) Histopathological examination of skin biopsy showing granulomatous inflammation and vasculitis. (D) Same patient with ulcerative changes in lesions within 2 weeks, suggesting necrotic ENL. This figure appears in color at www.ajtmh.org.

histological diagnosis of leprosy and leprosy reactions in the INFIR cohort of Indian patients with multibacillary leprosy. PLoS Negl Trop Dis 6: e1702.

2. Adhe V, Dongre A, Khopkar U, 2012. A retrospective analysis of histopathology of 64 cases of lepra reactions. Indian J Dermatol 57: 114-117.

3. Kumar B, Dogra S, Kaur I, 2004. Epidemiological characteristics of leprosy reactions: 15 years experience from north India. Int $J$ Lepr Mycobact Dis 72: 125-133.

4. Bala S, Sen S, Chatterjee G, Gangopadhyay A, 2014. Atypical erythema nodosum leprosum as the presenting feature in multibacillary leprosy: a case report. Indian J Dermatol 59: 94-95.

5. Sirka CS, Panda M, Pradhan S, Baisakh MR, 2017. Necrotic erythema nodosum leprosum healing with extensive scars. Indian Dermatol Online J 8: 509-511.

\footnotetext{
*Address correspondence to Tarun Narang, Department of Dermatology, Venereology and Leprology, 2nd Floor, Nehru Hospital, Sector 12, Postgraduate Institute of Medical Education and Research, Chandigarh, India 160012. E-mail: narangtarun@yahoo.co.in
} 